\title{
Teología del clamor popular
}

\author{
VICTOR CODINA \\ Centro de Investigación y Servicio Popular \\ Oruro, Bolivia.
}

\section{Novedad del tema}

Desde el seno de los diversos paises del continente está subiendo hacia el cielo un clamor cada vez más tumultuoso e impresionante. Es el grito de un pueblo que sufre y demanda justicia, libertad, respeto a los derechos fundamentales del hombre y de los pueblos" (Puebla 87).

Este clamor que Puebla constata, constituye el punto de partida de nuestra reflexión teológica. Nuestra teología arranca, pues, de este hecho histórico impresionante, sobre el que ya Medellín había llamado la atención: "un sordo clamor brota de millones de hombres, pidiendo a sus pastores una liberación que no les llega de ninguna parte. Nos estáis escuchando ahora en silencio, pero oímos el grito que sube de vuestro sufrimiento," ha dicho el Papa a los campesinos en Colombia"' (Medellín, Pobreza de la Iglesia, 2).

Y Puebla comenta asi este texto de Medellin: "el clamor pudo haber parecido sordo en ese entonces. Ahora es claro, creciente, impetuoso y, en ocasiones amenazante" (Puebla 89).

Cada dia hay en América Latina una conciencia más clara de este clamor, de este ensordecedor grito del pueblo latinoamericano que pide justicia y libertad. Los obispos y religiosos del NE del Brasil en 1973 escriben un documento titulado He oido los clamores de mi pueblo; Mons. Romero con frecuencia hablaba de cste tema: "el grito de liberación de este pueblo es un clamor que sube hasta Dios, y que ya nada ni nadie lo puede detener" (21.1.80). Y en su vibrante llamada profética a los soldados, lanzada la vispera de su asesinato, exclamó: "en nombre de Dios, pues, y en nombre de este sufrido pueblo, cuyos lamentos suben hasta el cielo cada dia más tumultuosos, les suplico, les ruego, ¡les ordeno!, en nombre de Dios: ¡cese la represión!"' (23.3.80).

Las citas pueden multiplicarse. Podriamos ver simbolizado este clamor la(inoamericano en los angustiosos gritos que lanzaba aquella pobre mujer brasileña torturada por la policía en Ribeirao Bonito, que provocaron la reacción 
en su ayuda del obispo Casaldáliga y del P. J.B. Penido Burnier: cesó la tortura, pero el $\mathbf{P}$. Joao Bosco Penido fue asesinado alli mismo. El pueblo luego arrasó la comisaria de policia y edificó alli una cruz y luego un icmplo como memorial del martirio.

Sin embargo, por habitual que resulte este tema en la teologia de América Latina, de no dejar de constituir una novedad en el panorama de la teologia contemporánea. Sobre el clamor de los pobres guarda silencio la mayoria de diccionarios e introducciones a la teología moderna como por ejemplo Sacramenumm mundi, Mysterium salutis, Concepros fundamentales de leologia, la Iniciación reológica de los dominicos franceses, la Sacra Theologiae Summa de los jesuitas españoles, los diccionarios y vocabularios bíblicos de Von Allmen, J.B. Bauer, M. Meinertz, H. Haag; sólo hallamos algunas breves referencias en F.X. Léon Dulour y Kittel.' Tampoco el mismo Vaticano II aborda explicitamente este tema, a pesar de su apertura al mundo contemporáneo.2

Si examinamos la tradición teológica clásica, constataremos que la Suma Teológica de Santo Tomás, sólo habla del clamor de Cristo en la cruz como algo milagroso que nuestra que entregó su alma voluntariamente ( 3 q 47, a 1 , ad 2), del grito de los animales en su dolor como forma de emitir el calor y los espiritus aumentados por el sulrimiento (1, 2ae, q 44, a 1, ad 2) y del clamor humano como fruto de la ira (2 2ae, q 158, a7 c).

Si vamos a la tradición espiritual, sobre todo del oriente cristiano, nos encontramos con la rica doctrina de la compunción (penthos) admirablemente recogida y expuesta por $\mathrm{I}$. Hausherr. ${ }^{3}$ La compuncion, que penetra la sensibilidad y estalla con Crecuencia en lágrimas, es la tristeza por la salud del alma perdida por el pecado. Es una gracia de Dios, que purifica el corazón y lo abre a los dones del Espiritu.

Es necesario, pues, diversificar los diversos tipos de clamor. En lodos ellos hay algo común: el clamor, como todas sus variantes (gemidos, quejas, lágrimas, lamentos, gritos, alaridos...), muestra una ruptura dolorosa en la persona, una situación de violencia, un sufrimiento agudo, que hace que la persona rompa su Iranquila armonia y estalle en expresiones de dolor y anguslia.

Aunque es dificil deslindar los diferentes niveles, podemos distinguir diversos lipos de clamor. Clamor de la naturaleza es el que brola de la misma limitación de la naluraleza humana, Trágil y débil. Desde el grito del niño que pide la leche materna, hasta el quejido del enferno, hay roda una gama de sufrimientos físicos y de dolor, que culmina en la misma muerte. Los limites entre esta dimensión natural del clamor y las otras dimensiones son difusos, pues la naturaleza está personalizada y es hisı́órica, pero hay ciertamente una diferencia. Clamor personal o existencial es el que nace del dolor moral, por ejemplo ante la muerte y sufrimientos ejenos, o el llanto de la compunción espiritual, que llega en los misticos a constituir un don del Espíritu. Clamor hisrórico y colectivo es la queja del pueblo que sufre injustamente la opresión.

A este clamor histórico y colectivo se refiere Medellin y Puebla, y sobre esic clamor queremos reflexionar. Se distingue del clamor natural y del exis- 
Iencial, de los cuales de algún modo la teologia y la espiritualidad siempre han hecho mención al tralar de las limitaciones y contingencias de la existencia humana, que nace entre lágrimas y muere entre lágrimas. Los escritos agustinianos serian un ejemplo de esta sensibilidad por el clamor existencial. Pero ahora nos hallamos ante algo nuevo y diferente, que no nace simplemente de la limiación metafísica de la humanidad ni lampoco del pecado de los particulares considerados aisladamente, sino de acontecimientos históricos y colectivos, iruto de la libertad y de opciones concretas e históricas.

No es casual el silencio de la cologia moderna del primer mundo sobre este tema, sino que es una muestra fehaciente de que la teologia está condicionada por el lugar social y teológico de donde se slabora. La leologia no es neutral, y no es indiferente hacer teologia desde el mundo de la riqueza de los paises del norte o hacerla clesde el reverso de la hisioria, desde los paises del sur. Hay lugares desde donde el clamor del pueblo apenas se escucha, en cambio, desde otros lugares el clamor es tumultuoso, impresionante, claro, creciente, ensordecedor. Basta salir a la calle: niños que juegan a barquitos en aguas sucias y negras de la calle, casas sin servicios, mujeres envejecidas prematuramente, viejos solitarios, campesinos polvorientos que venden sus pocos productos en el mercado, indigenas que cargan a sus espaldas muebles y pesados bulıos, gente que come en las aceras de la calle, lunerarias especializadas en niños a los que visten de angelitos blancos y alados, jóvenes en busca de trabajo, vendedores ambulantes, basurales llenos de perros hambrientos, casas pequeñas donde loda la familia vive en una habitación y duerme en una o dos camas., colas para pan, para fideo, para gas, coches desvencijados y viejos, mujeres que llevan garra ${ }^{2}$ de gas en una carretilla, universitarios que de noche estudian a la luz de los faroles de una plaza, aqui un borracho, allá vive una madre soltera, en aquella casila una familia cuyo padre murió de accidente en las minas, en aquella otra el hijo desapareció en la úlıima represión militar, más allá un comedor popular donde cada dia comen trescientos niños...

Y todo ello en paises ricos, con riquezas naturales, humanas y culturales, donde una minoría "herodiana" sive en plena abundancia y despillarro. Este clamor es amenazante, pues una siluación de injusticia permanente y prolongada no se puede sufrir indefinidamente. Nada violento dura.

Digamos para acabar esıa inıroducción que en los úllimos años lambièn el magisterio pontificio universal ha hablado de este clamor que sube el cielo y clama venganza. Pablo VI en su Populorum progressio (n. 30) habla de cllo y Juan Pablo II en su enciclica Laborem exercens tambićn (n. 8, 3) y cila algunos de los textos clásicos sobre el clamor (Gn.4,10; Sant.5,4). También el Consejo Ecuménico de las Iglesias publicó en 1980 un informe. Rumbo a ulla Iglesia solidaria con los pobres, en el que parte precisamente "del grito de los pobres."

\section{Relectura bíblica}

A pesar de que muchos diccionarios biblicos parecen ser sordos al tema del clamor popular, en realidad cuando se lee la Biblia desde csla perspectiva, se descubre que toda ella es una continuo clamor del pueblo, desde el Génesis 
al Apocalipsis. Sin pretender elaborar aqui ningún estudio bíblico exhaustivo sobre el tema, señalemos los capitulos más importantes de esta constante irrupción del clamor popular en la historia de salvación.

En el AT la palabra clamor (saaq) tiene según los especialistas (Gunkel, N.M. Sarna, P. Miranda, R. de Sivatte) un carácler técnico que equivale a "queja contra la injusicia inligida." T:n nuestro rápido sondeo por el AT recogeremos no sólo este término técnico, sino tambièn otros semejantes (gemidos, llantos, lamentos..) en la medida que expresen la queja del pueblo contra la injusticia. Dejamos a los especialisıas la profundización y ulterior precisión del lema.

Ya en las primeras páginas del Génesis encontramos el clamor de la sangre de Abel que sube al cielo:

Entonces Yahvé le dijo: Qué has hecho?. La voz de la sangre de tu hermano grita desde la ticrra hasta mi $(\mathrm{Gn} .4,10)$.

Pero será el Exodo el protoripo del clamor del pueblo. Las diversas tradiciones lo patentizan:

Los hijos de Israel sufrian bajo la esclavitud. Gritaban y su clamor subió hasta Dios. Oyó Dios sus lamentos, y se acordó de su alianza con Abraham, Isaac y Jacob. Y miró Dios con bondad a los hijos de lsrael y los atendió (Ex.2,23.25).

El clamor también está presente en la vocación de Moisés:

Yahvé dijo: he visı la humillación de mi pueblo en Egiplo y he escuchado sus grilos, cuando los maltrataban sus mayordomos. Yo conozco sus sufrimientos (..) Ve, pues, yo te envío al Faraón para que saques de Egipto a mi pueblo, los hijos de Israel (Ex.3,7.10;cfr. Ex.6,5;14;10;22,21-28).

Este clamor del pueblo que Yahvé escuchó, liberándolo de la opresión, forma parte del credo de lsrael:

Clamamos entonces a Yahvé, Dios de nuestros padres, y Yahvé escuchó nuestra voz, vio nuestra miseria, nuestras penalidades y nuestra opresión, y Yahvé nos sacó de Egipto con mano firme, demosırando su poder con señales y milagros que sembraron el terror (Dt.26,7-8; cfr Nm.20,16; Jos $24,7.)^{4}$

En los libros históricos, conlinuamente escuchainos el clamor del pueblo que sube hasta Yahvé pidiendo ayuda. Al entrar en la tierra prometida, los israelitas claman a Yahvé y éste los libera de sus enemigos (Jue. $4,3 ; 10,12 ; 15,18)$. Samuel unge a Saúl rey para que libere al pueblo de los filisteos por mandato de Yahvé, que ha visto la allicción del pueblo y ha escuchado su clamor $(1$ Sam.9,16). David agradece a Yahvé el haber sido liberado de las manos de Saúl:

Clamé a Yahvé en mi angustia

a mi Dios invoqué

y escuchó mi voz desde su templo

resonó mi llamada en sus oídos (2 Sam.22.7). 
Contrasta con la bondad de Yahvé que siempre escucha el clamor del pueblo afligido (Jdt.4,9:9,1; 2Cro.29,9; cfr. IMac.4,9-11.40; 9,46; 2Mac. 8,3 ..), la sordera de los ídolos que "tienen oidos y no oyen" (Sal.1 15,6) y que provoca las burlas del profeta Elias. Este les dice a los profetas de Baal en el monte Carmelo:

Griten más fuerte; cierto que Baal es Dios, pero debe estar ocupado, debe andar de viaje, tal vez esté durmiendo y tendrá que despertarse (2Re. $18,27)$.

El pueblo llora y gime al ir al desticrro, sicntc nostalgia de Sión (Sal.137), pero a su regreso el llanto se convierte en alegria:

Cuando el Señor cambió la suerte de Sión, creíamos soñar,

se nos llenaba la boca de risa

y los labios de alegria (Sal. 126,1-2).

A la vuelta del exilio, Esdras resume la historia de salvación de Israel en estos párrafos:

Durante su opresión clamaban a tí y tú los escuchabas desde el cielo, así que por tu inmensa bondad, les mandabas salvadores que los liberaron de sus opresores.

Pero cuando respiraban de nuevo, hacian el mal contra ti, y lú olra vez los dejabas en manos enemigas que los oprimían. Ellos de nuevo clamaban hacia tí, y tú escuchabas desde el cielo y por tu gran bondad los salvaste muchas veces (Neh.9,27-28).

Esta dialéclica pecado-salvación, se manifiesta claramente en los profetas.

Por una parte, en el cántico de la viña, Isaías se queja amargamente en nombre de Yahvé:

El esperaba rectitud

y va creciendo el mal;

esperaba justicia

y sólo se oye el grito de los oprimidos (Is. 5,7).

Ahora es el mismo Israel el que esclaviza a sus hijos. La riqueza de los opresores que construyen casas con riquezas injustas, clama al cielo:

Contra tí grita una piedra de tu muro,

y las vigas del techo le responden (Hab.2,11).

La condición para que Yahvé escuche el clamor del pueblo es que éste practique la justicia:

Entonces clamarás a Yahvé te responderá,

Pedirás socorro y dirá: "Aqui estoy."

Si en tu casa no hay más gente explotada, si apartas el gesto amenazante

y las palabras perversas;

si das al hambriento lo que deseas para ti 
y sacias el hambre del oprimido (Is.58,9-10).

La dureza de corazón del pueblo, provocal las lamentaciones de los profetas, que anuncian los desastres de la hija de Sión (Lam. 1, 4.8.11.22; 2, 18; $3,56$; Jer. 11,$11 ; 31,15 ; 14,2 ; 18,22 ; 8,19 ; 20,16 ; 30,15)$. El pucblo gime como mujer con dolores de parto $(1 s .26,17)$. Pero los profetas anuncian liempos mejores y un futuro escatológico de go/o:

$\mathrm{Si}$, pueblo de Sión, que vives en Jerusalén, ya no llorarás más. E.l se compadecerá de li, al sentir tus lamemos, y le atenderai inmedialamente (ls.30. 19).

El lín, ell el cielo nucvo y la lierra nucva:

Ya no se sentirán, en adelante sollozos de tristera, ni grilos de angustia (Is. 65,19 ; cir Is 35,$10 ; 51,11$ ).

Job representa precisamente un enigina insoluble para el hombre del Antiguo Testamento: ¿Cómo Dios nos escucha el clamor de un hombre justo? (Job. 30,$20 ; c\{r 19,7 ; 34,28)$. Esta pregunta de Job quedará sin respuesta hasta que el Padre resucite a Jesús de entre los muertos.

Los Salmos son un constante clamor del pueblo a Dios, ya que aunque su forma sea a veces en singular, son siempre una oración colectiva. El pueblo que sufre, que se siente perseguido, deslerrado, en desgracia, en manos de sus enemigos, abatido y probado, eleva a Yahvé su clamor y éste le escucha:

Desde el abismo clamo a tí, Señor,

Escucha mi clamor,

Que tus oídos pongan atención

a mi voz suplicante (Sal.130, 1-2; cfr Sal 3,5; 77,2; 142,2; 17,6;

$27,7: 55,17 ; 61,3: 86,3 ; 86,7 ; 69,4 ; 102,2 ; 5,2: 9,15 ; 38,10 ; 102,6$;

$22,3 ; 57,3: 141,1 ; 88,2 ; 141,1 ; \ldots)$.

Los Salmos de acción de gracias no son más que la respuesta agradecida de Yahvé que ha escuchado el clamor del pueblo en el momento de peligro:

Clamaron al Señor en sus angustias,

y él los libró de sus aflicciones (Sal. 108,13; cfr 18,7; 30,3; 66,17;

$28,1 ; 65,14 ; 4,4 ; 141,1 ; 120,1 ; 34,7 ; 22,6 ; 79,11 ;)$.

Por eso Jonás, desde el vientre de la ballena presupone que Dios ya ha escuchado su oración:

En mi angustia llamé a Yahvé,

y me respondió

grité desde el lugar de los muertos

y tú oíste mi voz (Jon.2,2).

Para acabar este breve recorrido veterolestamentario del clamor, cilemos dos textos de Proverbios. Uno nos recuerda las condiciones necesarias para que nuestro clamor sea escuchado por Dios:

Quién cierra los oídos a las súplicas del débil,

clamará también él y no hallará respuesıa (Prov. 21,13). 
El segundo texto nos da la clave para comprender de dónde nace el clamor del pueblo:

Cuando los justos crecen, el pueblo se alegra,

Cuando dominan los inalos, gime el pueblo (Prov. 29,2).

La temática del clamor no es exclusiva de AT, sino que irrumpe en el nismo NT. El clamor del pueblo que sufre opresión y marginación, se personilica en el clamor de los pobres y enfermos que suplican a Jesús con grandes voces (M1.9,25; 15,22-23; Mc.9,23-24), como el caso del ciego de Jericó:

Al enterarse de que era Sesús de Nazareth, se puso a grilar: ¿Hijo de David, Jesús, ten compasión de mí! (Mc. 10,47; c\{r. M1.20,29-34; L.c.18,35-43),

O la mujer cananea quc:

Se puso a griıar: jlen piedad de mi, Señor, Hijo de David! Mi hija es alormentada por un demonio (Mt.15, 22; cfr. Mc.7,29-30).

A rodos ellos Jesús los escuchó y los samo:

El episodio de Pedro caminando sobre las aguas y que grila: "Señor sálvame'", al comenzar a tener miedo y a hundirse (Mi.14,30) resume todo el clamor del Exodo: Jesús, como Yahvé en otro tiempo, escucha su clamor y lo salva del peligro de las aguas de la muerre, como salvó al pueblo del faraón en el Mar Rojo.

Pero en el NT encontramos el clamor del mismo Jesús:

Cristo en los dias de su vida mortal, ofreció su sacrificio con lágrimas y grandes clamores. Dirigió ruegos y súplicas a Aquél que lo podía salvar de la muerle y fue escuchado por su religiosa sumisión (Hb.5,7).

Este clamor de Jesús en los dias de su vida mortal, alcanza su punto álgido en la pasion y en la muerte. El grito de Jesús en la cruz, quejándose de haber sido abandonado por Dios (Mi.27,46; Mc.15,34) y su grito final de entrega al Padre (MI.27,50; Lc.23,46; Mc.15,37), compendian el clamor de todo el pucblo a lo largo de su historia. La historia de Jesús es una historia marcada ya desde el comienzo por la contradicción y la persecución: la sangre de los niños inocentes asesinados por Herodes, se eleva al cielo como el llanto de Raquel por sus hijos (Mt.2,18; cfr. Jr. 31, 15).

La muerle de Esteban, cuyo martirio es visto por Lucas en paralelismo con la muerte de Jesús, también termina en un gcito prolundo (Hch.7,60).

Para Pablo los bautizados hemos recibido el Espiritu de filiación, el cual enviado a nuestros corazones nos hace clamar, ;Abba, Padre! (Rm.8,15; Gal. 4,6). Este Espiritu intercede por nosotros con gernidos incnarrables $(R m .8,26)$, esperando la liberación definitiva:

Vemos como todavía el universo gime y sufre dolores de parı. Y no sólo el universo, sino nosotros mismos, aunque se nos dió el Espiritu como un anticipo de lo que tendremos, gemimos interiormente, esperando el dia en que Dios libere nuestro cuerpo (Rri. 8,22-23).

Vivimos, pues, sujetos a la opresión y a la injusticia. La carta de Santiago 
es terminante:

¿Cómo clama el salario que no han pagado a los que trabajaron en la cosecha de sus campos!. Las quejas de los segadores han llegado a oidos del Señor de los ejércitos (Sanı.5,4-5; cfr 4,9).

El NT se cierra con la esperanza gloriosa de la nueva Jerusalén, en la que Dios estará con su pueblo y

Enjugará toda lágrima de sus ojos, y ya no existirá ni muertc, ni duelo, ni gemidos, ni penas, porque todo lo anterior ha pasado (Apoc. 21,4).

Alli el clamor se convertirá en grito de exultación y de alabanza (Apoc 19), mientras se oirán las lamentaciones por la caida de Babilonia, la ciudad opulenta y poderosa (Apoc. 18).

Toda la Escritura leida desde el clamor del pueblo, adquicre una especial resonancia. La Biblia no es una simple meditación metafísica sobre la brevedad de la vida humana, sino la historia de la aflicción del pueblo oprimido que busca su liberación, una revelación hisıórica sobre el Dios que escucha el clamor del pueblo, convierte las lágrimas en risas y las risas en lágrimas: los que ahora lloran, reirán, y los que ahora rien, llorarán (Lc.6,21.25). Los impios ahora se ríen del justo y lo desprecian, pero un dia el Señor se reirá de ellos (Sab. 4,18 ). Los nuevos diccionarios bíblicos no deberian ya ignorar este tema...

\section{La voz de la tradición}

Sería extraño que la tradición de la Iglesia no hubiese desarrollado este tema. Espigando las homilias de los Padres de la Iglesia, hallamos textos significativos. Basilio escucha en el oro acumulado el clamor de los pobres explotados:

A li te agrada sobremanera el bello color del oro, pero no consideras cuántos gemidos de miserables te van siguiendo. 5

Los pobres clamarán contra el rico el día del juicio:

Qué defensa tendrás cuando todos aquellos a quienes agraviaste te rodeen por doquiera y clamen contra tí en presencia del justo Juez?... Un coro malo de lamentaciones te seguirá como una muralla. ${ }^{6}$

Y aplicando la parábola de Lázaro y el rico a su tiempo, Basilio exclama:

No pasemos de corrida por junto a los Lázaros, que también ahora yacen ante nuestros ojos (...), ni imitemos al rico sin entrañas si no queremos ir al fuego del infierno al que él vino a parar (...). Muchos rogaremos entonces a Abraham (...). Cada uno de aquellos (Lázaros) gritará contra nosotros: "no busques la misericordia que tú no practicaste con los demás"... Esıo nos dirán, y no sin razón. Y aún me temo que nos lancen palabras más amargas que ésas, pues superamos en maldad al rico del evangelio. ${ }^{7}$

Semejantes expresiones hallamos en Juan Crisóstomo: 
Si miras por el contrario al avaro y rapaz, oirás que se dicen: ¡Abominable, malvado, criminal! ¿Qué mal te ha hecho? A mi, ninguno, pero sí a mi hermano. Contra èl se levantarán a diario mil clamores.

Los bienes robados claman contra el rico aun después de su muerte:

Y cuanto los bienes son más estables, tanto más persistente es la acusación. Esas grandes y espléndidas casas, aun después de muertos sus dueños, eslán ahi levantando voces de durisima acusación.

Y comentando Mi.25, Crisóstomo escucha en el clamor del pobre el grito de Cristo:

Cierto que lo que aparece ante tus ojos no es Cristo, pero El es quien en esa figura te pide y recibe. Avergüénzate, pues, cuando te pide y no le das. Porque esıo sí que es vergüenza, esto sí que merece castigo y suplicio. Que El le pida, obra es de su bondad, y ello ha de ser motivo de nuestro orgullo, pero no darle lo es de lu crueldad. Y si ahora no crees que, al pasar de largo por junto un cristiano pobre, pasas de largo junto a Cristo, día vendrá en que lo creerás cuando, poniéndote delante de ellos, te diga: "Cuanto no hicistéis por èstos por mi no lo hicisteis" (Mt.25,45). ${ }^{10}$

La condición de ser escuchada nuestra oración, es escuchar nosotros el clamor del pobre:

Tales eran las oblaciones de Cornelio: Tus oraciones y cus limosnas -dice el autor sagrado - han sido recordadas en el acatamiento de Dios (Hch 10,4). He aquí una hermosa conexión: somos escuchados cuando escuchamos a los pobres que se nos acercan. El que cierre - dice la escritura- sus oidos para no oír al pobre, tampoco Dios lo oirá en su oración" (Prov. $21,13) .11$

Ya en plena época medieval, "el último de los Padres de la Iglesia," S. Bernardo, no teme aplicar esta doctrina del clamor de los pobres a los mismos obispos:

Claman los hambrientos, se quejan y dicen: "Digan, pontifices, ¿qué hace cl oro en el freno del caballo? ¿Acaso el oro en el freno mitiga el frío o el hambre? ¿De qué sirven tantos vestidos colocados en el armario? Nos quilan cruelmenle, lo que gastan vanamente. Pues también nosotros hemos sido creados por Dios y redimidos por la sangre de Cristo. Somos, pues, hermanos de usledes. ${ }^{12}$

Si pasamos ahora a América Latina, no será extraño que hallemos textos semejantes en los obispos de los siglos XVI y XVII, protectores de los indios. Fray López de Solís, obispo de Perú escribe:

Los clamores destos naturales por los grandes y muchos agravios que reciben de los españoles les llegan a los oydos de Dios. ${ }^{13}$

E] Obispo Juan del Valle no teme comparar la opresión de los indios a la de los israelitas en Egipto:

De manera que paresce esta tierra más tierra de Babilonia que de Don Carlos, y a esta causa no a abido doctrina ni la puede aver entre los natura- 
les... es cierto son más fatigados que los Israelitas en Egipto. ${ }^{14}$

Y el obispo Juan de Medina, escribe el 13 de octubre de 1583 desde Michoacán unas palabras que parecen ser un comentario del Génesis sobre el clamor de la sangre de Abel:

Mucha de la plata que acá se saca y va a esos Reynos, se beneficia con la sangre de Yndios y va envuelta en sus cuevas. ${ }^{15}$

Este clamor lo podemos ver simbolizado en los gritos de aquella joven marcada a fuego en su rosiro, de la que nos hablan una de las cartas a la Corona Española:

Les hierran el rostro como esclavos y pasan de unas manos a otras vendidos, y ha havido muchacha que viéndose herrar daba voces diciendo: no me hierre, soy hija de christiana española de las captivas que tienen los yndios, y soy informado que aviéndola herrado la enbiaron a las hijas del Virrey, marqués de Guadalcázar. ${ }^{16}$

Podemos concluir que siempre que la Iglesia ha sido sensible al clamor de los pobres, el evangelio ha podido ser predicado y la comunidad cristiana ha crecido en fidelidad a Jesús. Si en América Latina los grandes obispos de la primera época de la colonia pudieron realmente evangelizar, fue porque antes de predicar supieron escuchar el clamor de los indios..$^{77}$ Basten estas breves notas de la tradición, para pasar ya a una reflexión más sistemática sobre el clamor del pueblo.

\section{Reflexión teológica}

Tras esta relectura bíblica y de la tradición desde el clamor de los pobres, aparece claro que nos hallamos ante una dimensión fundamental de la revelación, que las circunstancias de hoy nos obligan a redescubrir y a resaltar de forma nueva. Se trata no simplemente del misterio del mal o del dolor humano sino de un aspecto muy concreto del mal: el sufrimiento injusto ińligido al pueblo, el clamor colectivo e histórico del pueblo. Pero es necesario profundizar teológicamente en este clamor popular.

El clamor como expresión del pecado. El clamor del pueblo, tal como se vive hoy en América Latina y como ha aparecido a lo largo de la historia de salvación, no es simplemente algo natural, fruto de la fatalidad de la naturaleza, sino que tiene un claro carácter de sufrimiento causado al pueblo por fuerzas históricas concretas. Es un acto de violencia infligido al pueblo por los poderes del mal. El dolor del pueblo es fruto de la injusticia. El lamento del pueblo es la expesión de una contradicción tanto más hiriente, cuanto es arbitraria y libre: hay un Cain que mata al hermano, un Faraón que oprime al pueblo, unos poderosos que lo explotan, unos extranjeros que lo dominan y esclavizan, unos herodes que provocan matanzas de inocentes, unos sacerdotes y fariseos que los acechan y aprisionan, unos pilatos que lo crucifican. Todos estos personajes adquieren diversos nombres a lo largo de la historia, nombres personales y nombres colectivos, nombres de estructuras económicas, sociaies y politicas, nombres de divinidades de la muerte: egipcia, babilónicas, griegas, 
romanas, hispánicas, inglesas, norteamericanas...

El clamor del pueblo, sus lamentos que suben al cielo, son la expresión de un no-deber-ser, de algo contrario a los planes de Dios, opuesto al reino. Es una denuncia airada, una queja llena de indignación hisıórica. El clamor del pueblo es lo más opuesto a una tranquila aceptación fatalista de la realidad o a una postura alienante.

El clamor, a veces sordo, a veces convertido literalmente en lamentos es la manifestación de la negatividad del pecado que debe ser ncgada. El clamor impide considerar la realidad histórica del pueblo, cono algo nalural, como pequeños errores marginales de una historia que progresa y avanza. El clamor es una crítica al optimismo desarrollista de los paises y clases ricas y una afirmación de la realidad del pecado, que nace de las personas y cristaliza en estructuras.

En frases de Puebla: "en esta angustia y dolor, la iglesia discierne una situación de pecado social, de gravedad tanto mayor por darse en paises que se llaman católicos y que tienen capacidad de cambiar' (Puebla 28).

El clamor como acusación que pide venganza escarológica es otra dimensión teológica del clamor: clama venganza al cielo, desde la sangre de $A b e l$ (Gn. 4,10 ) hasta el salario negado a los trabajadores (Sant 5,4-5); este llanto es fruto del pecado de personas y grupos que rien:

Como un collar van luciendo su orgullo,

Por ropa llevan puesta la violencia,

Transpiran por sus poros la maldad,

Su corazón desborda

De planes ambiciosos.

Se burlan y hablan mal de los demás,

Con soberbia profieren amenazas;

hablan de que son dueños del cielo

y recorren la tierra con su lengua (Sal.73,6-10).

En Lucas las bienaventuranzas van acompañadas de las maldiciones: después de llamar bienaventurados a los que lloran (Lc.6,21) se añade "¡Pobres de ustedes los que ahora rien, porque van a llorar de pena!" (Lc.6,25).

El llanto del pueblo es fruto de la risa satisfecha de los ricos que oprimen. Mientras Herodes celebra la fiesta de su cumpleaños, Juan Bautista es decapitado; mientras Somoza baila, en sus cárceles es torturado el pueblo. La riqueza de los ricos es robada a los pobres, y por esto, como afirman los profetas antiguos y nuevos, de las casas de los ricos salen voces que claman venganza: son las voces de los pobres empobrecidos, sean éstos los Judios de Jerusalén, los mendigos de Constantinupla, los indios de Potosi, o el tercer mundo de hoy. La dialéctica llanto -risa, es la respuesta biblica a la cuestión del problema del clamor del pueblo: el llanto del pueblo es consecuencia de la risa de los poderosos.

Pero esta dialéctica un día será invertida. Si el llanto del afligido conmueve a Dios, la risa del satisfecho provoca su ira. Los que con sus justicia 
esclavizan a sus hermanos y mantiene cautiva la verdad de Dios, provocan la ira de Dios $(\mathrm{Rm} .1,18)$. El llanto de los pobres pide justicia y venganza escatológica. En el juicio la dialéctica se invertirá: los que ahora lloran, reirán; los que ahora rien satisfechos de su preopotencia, llorarán.

El tema de Lázaro y el rico (Lc.16,19-31) y del juicio final (Mt.25,31-46) adquiere una gran fuerza reológica e histórica. Los Padres de la Iglesia aplican estas escenas a los ricos de su tiempo; el Papa Juan Pablo II en la encíclica $R e$ dempior hominis habla de que la parábola de Lázaro tiene hoy dimensiones mundiales $(\mathrm{RH}, 16)$ y recientemente en una homilia sobre Mateo 25 en Canadá, aplica el evangelio del juicio final a los pueblos del norte y del sur:

Por ello habla Cristo Juez de "mis humildes hermanos" y a la vez se refiere a cada uno de lodos.

$\mathrm{Si}$, se está refiriendo a la dimensión universal total de la injusticia y del mal. Está hablando de lo que hoy solemos llamar contraste Norte-Sur. No sólo Oriente-Occidente, sino también Norte-Sur, el Norte cada vez más rico y el Sur cada vez más pobre.

Si, el Sur progresivamente más pobre y el Norte aumentando siempre su riqueza. Más rıcos en recursos de armas con los que la superpolencias pueden amenazarse y se amenazan mutuamente (...).

Y sin embargo, a la luz de las palabras de Cristo, este Sur pobre juzgará al opulento Norte. Y los pueblos pobres y las naciones pobres - pobres de modos distintos, no solo faltos de alimentos, sino también privados de libertad y de otros derechos humanos- juzgarán a los que le arrebatan estos bienes, acumulando para ellos el monopolio imperialista de predominio económico y político a expensas de otros. ${ }^{18}$

El clamor del pueblo pobre no sólo es un lugar teológico, sino que es también un lugar escatológico. En ellos se adelanta ya el jujcio de Dios sobre la hitoria. Frente a una imagen de un Dios bonachón que parece no tomar eri cuenta el pecado ni la injusticia, el clamor de los pobres nos revela la ira de Dios hacia los que hacen llorar al pueblo. El sur juzgará al norte, los campesinos desnutridos, los mineros con silicosis, los torturados por las dictaduras, juzgarán al mercado común, a la CIA, al Fondo Monetario Internacional, a la O.N.U., a la escuela de militares de Panamá, a la Trilateral, a Norteamérica...

Los pobres son el tribunal supremo de la historia. Un día Dios se reirá de los que ahora se ríen (Prov. 1,26).

El clamor del pueblo como grito del crucificado. El clamor del pueblo oprimido y sufriente posee una dimensión cristologica. Los sufrimientos del pueblo alcanzan su punto álgido en los sufrimientos de Cristo. La sangre de Crislo clama a Dios con más fuerza que la sangre de Abel (Hb.12,24). El clamor del pueblo culmina en los gemidos de Jesús en su vida mortal (Hb.5,7) y en su cruz. El abandono del pueblo sufriente (Sal.22,2) se expresa en el grito de abandono de Jesús en Cruz (Mt,27,46; Mc.15,34).

Los sufrimientos de Israel en el Exodo, son figuras del misterio pascual de Jesús (1 Cor. 10,1-6). Como Moisés prefírió compartir los malos tratamientos 
del pueblo de Dios antes que las riquezas del faraón (Hb.11,25-27), Cristo se solidarizó con su pueblo en lodo menos en el pccado (Hb.4,17) y fuc probado en el sufrimiento (Hb.2,18).

Pero esta perspectiva debe completarse con otra. En el sufrimiento del pueblo clama Cristo; en los pobres que clama Cristo clama hoy (Mt.25,31-46). Hay pues una misteriosa, pero real identıficación entre el clamor del puctolo y cl clamor de Cristo, entre el pueblo hoy crucificado y el Cristo crucificado. Tanto la pasión de Cristo como la del pueblo se deben a causas históricas reales, fruto de acciones históricas y de pecados históricos. El pueblo crucificado de hoy prolonga la pasión de Cristo, y a ambos se aplican legítimamente los cantos del misterioso Siervo de Yahvé (Is.42,1-4; 49;51; 53): desırozados por la intervención histórica de los hombres, considerados como leprosos y condenados por los demás, aparecen como pecadores, aunque en realidad sufren por los pecados ajenos y expian los pecados de los otros, constituyéndose en realidad en salvadores por su sacrificio. En medio de su sufrimiento hay esperanza de que un día triunfará el derecho y la justicia. ${ }^{19}$

El pecado del mundo es la crucifixión de Cristo, y este pecado se prolonga en el pueblo crucificado, por los herodes y pilatos de hoy, los sacerdotes y fariseos, la Pax Romana y la teocracia judía, que crucificaron a Cristo, se prolongan en los que continúan crucificando al pueblo hoy. Cierta teología y espiritualidad que se limita a contemplar y celebrar al resucitado, olvidando que estamos en tiempo de pasión, no hace justicia al crucificado presente en los crucificados de este mundo. Escuchar el clamor del pueblo es siempre un correctivo de la continua tentación de evacuar la cruz de Cristo, que el racionalismo y el esteticismo de todas las épocas de optimismo materialista consideran locura absurda (1 Cor. 1,17-24). Sobre todo los sabios y prudentes de este mundo tienen peligro de olvidar que Dios escogio lo necio y débil para avergonzar a los fuertes y poderosos (1 Cor.1,26-29). El misterio de la cruz esencial al cristianismo, se revela continuamente a los pequeños y sencillos (c「r. Lc. 10,21; Mt. 11, 25-27) no de forma intelectual, sino existencial: en ellos continúan gritando el crucificado.

Bartolomé de las Casas oirá en el clamor de los indios, el clamor del crucificado: "yo dejo en las Indias a Jesucristo nuestro Dios, azotándolo y afligièndolo y crucificándolo no una sino millones de veces." 20 La moderna teologia del Dios crucificado (Kitamori, Moltmann, Evdokinov), encuentra desde esta perspectiva del clamor del pueblo un impresionante realismo hislórico: Dios sigue siendo crucificado hoy en los paises del sur, por los países del norte. No se trata de una piadosa consideración, sino de una verdad dogmática.

El clamor del pueblo como oración. Es tan evidente en la Escrilura la auténtica definición de la oración es el clamor del pueblo.2l El clamor del pueblo oprimido sube a Dios, clama al cielo, desde Egiplo hasta los desterrados en Babilonia, desde los Salmos hasta los pobres marginados que se acercan a Jesús, desde Pedro que se hunde en las aguas hasta Esteban que muere como Jesús clamando al Padre. Nada más ajeno a la Biblia que una oración meramente filosofica o estética, al margen de la historia y de la vida. Esto es tan evi- 
dente, que la misma lglesia en su liturgia pide al seffor que "llegue a El su chmor." Esto debería hacer pensar a cuantos hoy parecen limitar la oración a un entusiasmo aleluyático, al margen del clamor del pueblo. Una oración que no escuche el clamor del pueblo, no puede ser escuchada por Dios, como afirma la Escritura (Prov. 21,13) y recuerdan los Padres.

No es casual que en América latina hayan surgido versiones de los Salmos como esta:

Escucha mis palabras, ;oh Señor!

Oye mis gemidos.

Escucha mi protesta

Porque no eres tú un Dios amigos de los dictadores,

Ni partidario de su política,

Ni le infuencia la propaganda,

Ni estás en sociedad con el Gansgter. ${ }^{22}$

Pero la identificación de la oración con el clamor del pueblo debe ser profundizada. Esta oración se dirige a Dios, es un clamor confiado al Dios de la vida, precisamente cuando se experimenta la muerte. Es una oración desde el abismo, desde la fosa, desde el vientre del monstruo, desde el Seol. Y esta oración es escuchada por Dios. El Dios biblico, a diferencia de los ídolos, escucha el clamor del pueblo en aflicción.

He aqui un misterio, que podríamos llamar "el misterio de la lágrima." El clamor del pobre llega a Dios, no porque el pobre sea siempre moralmente bueno y puro, sino porque padece. Si Dios libera y salva al pueblo no es porque el pueblo sea bueno, sino porque Dios es bueno, tierno y compasivo, y las lágrimas del que sufre, sobre todo del que sufre por culpa de otros; conmueven su corazón paterno. En este misterio de las lágrimas que conmueven las entrañas de Dios (cfr.Lc.15,21), el corazón de Jesús (Mc.6,34), secompendia el misterio de la salvación, la teologia de la gracia de Dios, la prioridad del amor de Dios, la doctrina de la justificación no por las obras, sino por la fe. No deja de ser sintomático que fuesen los tariseos, los ricos y los poderosos del tiempo de Jesús, los que se escandalizasen de que él comiera con pobres y pecadores (Lc. 15, 1-2; Mc. 2,16). Los ricos de la historia no comprenden la misericordia de Dios, se sienten justos y no necesitados de salvación, como el fariseo de la parábola ( $L c .18,9-14$ ) y como los saduceos que no esperan nada después de esta vida (Mi.22,23). Son los que rien, los que ríen salisfechos de la vida, los que son incapaces de orar.

El punto álgido del clamor que sube al cielo, fue el de Cristo en la cruz. Su oración rue escuchada (Hb.5,7). El rruto de la oracion de Jesús fue su resurrección. Jesús es el nuevo Jonás, que habiendo descendido al corazón de la tierra, a los infiernos (Mt.12,40; Lc 11,30) es resucitado por el Espiritu del Padre (Rm. 8,11) no permitiendo que fuese abandonado en el Hades (Hch.2,24-31). El Dios de la vida, "que da vida a los muertos y llama a las cosas que no son para que sean" $(\mathrm{Rm}, 4,18)$, hace pasar a Jesús de la muerte a la vida plena y definitiva. El Espírilu de vida realiza en la pascua de Jesús su obra maestra: la re- 
surrección.

El pueblo crucificado confia plenamente en que el Señor escucha su oración, aunque sea de un modo tan misterioso como la respuesta del Padre a la oración de Jesús en su pasión. El pueblo confia que su clamor llega al cielo y que Dios lo liberará, como liberó al pueblo en Egipto, aunque esta liberación implique compromisos, luchas, y una larga marcha hasta llegar a la tierra prometida.

En el clamor-oración del pueblo gime el Espiritu con gemidos inenarrables, haciendo que su dolor no desemboque en la desesperación, ni en un nihilismo cínico. El Espiritu es quièn nos hace clamar ¡Abba, Padre! (Rm.8, 26; Gal.4,6).

¿Cómo explicar la paciencia y la resisıencia del pueblo crucificado en sus sufrimientos si no es por la presencia del Espiritu que mantiene en él la esperanza y la confianza en que el Padre no le abandonará en el infierno del dolor? ¡Cómo contrasta con la incapacidad de los ricos ante el sufrimiento!: acostumbrados a conseguirlo todo con dinero, se desesperan ante el menor contratiempo; satisfechos del presente, no esperan del futuro y temen el sufrimiento y la muerte. La riqueza impide orar. Sólo el clamor del pueblo y la solidaridad con los que claman es escuchado por Dios.

El clamor del pueblo como dolores de pario. El clamor del pueblo se enmarca en el clamor de toda la creación que ha sido esclavizada por el pecado y espera su liberación: "pues sabemos que la creación entera gime hasta el presente y sufre dolores de parto" (Rm. 8,22).

El clamor del pueblo es el dolor del parto, es el sufrimiento de la mujer encinta que gime; pero su dolor se transformará en gozo de alumbramiento de un nuevo ser (Is. 13,8; 37,3; Os. 13,13; Jn. 16,21).

El pueblo en su sufrimiento, como Cristo en la cruz, confia que su dolor no será estéril: algo nuevo va a nacer de tanto sufrimiento y de tanta sangre.

La esperanza de Mons. Romero de que resucitaria en el pueblo salvadoreño, la esperanza de tantas madres que ven morir a sus hijos de forma absurda, es una esperanza de un alumbramiento nuevo. Casaldáliga lo ha expresado con su acostumbrada fuerza profética:

Que las Madres de la Plaza de Mayo

-alaridos de América en dolores de parto-

consigan dar a luz

al Hombre Nuevo,

el Pueblo libre,

La Gran Patria Amerindia, negra, criolla, ella. ${ }^{23}$

La hora del parlo es un "Kairós" (2 Cor.6,2), un tiempo propicio de salvación América latina, el pueblo, es como la mujer del Apocalipsis que grita con los dolores de parto y tiene frente a sí el dragón dispuesto a devorar a su hijo (Apoc. 12,1-6). Es momento de lucha y de esperanza, algo nuevo está naciendo. 
El clamor del pucblo es un anhelo del reino, es clamor del reino yue csá Ilegando. El dolor anuncia un fuluro mejor, es un signo prognóslico del reino deliniijo, del cielo nuevo y la lierra nueva, donde no habrá ya lianou ni dolur. ni gritos (Apoc. $21,1-4$ ).

De esta forma el clamor del pueblo no es sólo una a firmación del reino como negación de la negatividad presente, sino un alumbramienıo del reino: esıá naciendo ya el Hombre Nuevo, la Mujer Nueva, la Tierra Nueva. La solidaridad, la lucha, la esperanza, el compartir, el dar la vida, la confianza en Dios, son ya primicias de resurrección. Nace una nueva espiritualidad, ${ }^{24}$ nace una nueva praxis, nace una nueva realidad, nace una pequeña semilla, una "flor sin defensa" (C. Mesters), una nueva forma de comunidad eclesial y una nueva Torma de comunidad humana. Posee la fragilidad de lodo lo evangélico, la pequeñez de la semilla, la novedad de todo lo que no nace de la carne ni de la sangre, sino del Espíritu. De la muerte nace la vida, del parto brota la esperanza, del dolor la alegria. Más aún, simultáneamente hay dolor y gozo, es un parto largo, pero se oyen ya gritos de victoria. El parto impide lanto el fatalismo (hay esperanza de liberación), como el fanatismo milenarista (conlinuará el dolor hasta el final de la historia). La salvación es objeto de esperanza, pero tanto uno como otra tienen ya dimensiones históricas:

"Aquellos que siembran con lágrimas, cosechan entre gritos de júbilo" (Sal. 126,5).

\section{Interpelación}

Signos de los tiempos.

La poderosa y casi irresistible aspiración de los pueblos a una liberación, constituye uno de los principales signos de los tiempos que la Iglesia debe discernir e interpretar a la luz del evangelio. Este importante fenómeno de nuestra época tiene una amplitud universal, pero se manifiesta bajo formas y grados diferentes según los pueblos. Es una aspiración que se expresa con fuerza, sobre todo en los pueblos que conocen el peso de la miseria y en el seno de los estratos sociales desheredados. 25

Estas importantes palabras de la Instrucción de la Congregación para la Doctrina de la Fe, resumen el sentido del clamor del pueblo en América latina hoy: es un signo de los tiempos. Esto explica tanto su novedad como su profundidad. Silenciado duranle años, hoy adquiere una relevancia peculiar, y no sólo para los paises de América latina y del tercer mundo, donde este clamor se oye con mayor intensidad. Todo el mundo debe inıentar escucharlo, discernirlo, interpretarlo, dejarse interpelar por él. Pero su misma escucha supone un esfuerzo de cercania, no pasar de largo como el sacerdote y el levila de la parábola del buen samaritano. Pero no basta escuchar este clamor. Este grito del pueblo oprimido, interpela y exige una respuesta. Y cualquier respuesta supone una conversión. La doctrina tradicional de la espiritualidad sobre la conversión mantienc su actualidad hoy, si se traduce en una exigencia de conversión evangélica personal y colecliva, que nos haga clamar como la célebre “Oración de Jesús" Oriental: “¡Jesús Hijo de David ten compasión de no- 
sotros!." Se exige una conversión hacia el clamor del pueblo: hemos de pasar de las lágrimas de la compunción a la solidaridad con los que lloran injustamente. Esta conversión exige no sólo un cambio de mentalidad, sino de actitud y de praxis.

Interpelación teológica. La auscultación de este signo de los tiempos implica a nivel teológico una serie de reformulaciones. Baste resumir las principales, que ya han ido apareciendo a lo largo de estas páginas.

El pecado parece como una realidad histórica, presente y grave, que violenta el plan de Dios y ejerce violencia sobre el pueblo condenándolo a una muerle prematura. Dios queda definido como el Dios de la vida, que escucha compasivo el clamor del pobre que sufre injustamente y lo libera de la muerte, mientras se indigna contra el poderoso que rie satisfecho y es culpable de tanta muerte. Cristo se solidariza con el clamor del pueblo, hasta constituirse el mismo como en el símbolo del sufrimiento y del pecado del mundo. El es la voz de los que gimen y claman, de tal forma que continúan clamando a través de los crucificados de este mundo. El clamor de los pobres es sacramento de Cristo. La respuesta del Padre al clamor de Cristro en la cruz es garantía y esperanza de liberación plena para todos lo que sufren injustamente: la resurrección. Por otro lado, el clamor es un signo escatológico que anuncia el juicio de Dios sobre los opresores y anticipa el cielo nuevo y la tierra nueva en un parto doloroso. A través de este clamor gime el Espiritu que va transformando la esclavitud en liberación y libertad. Pero esta liberación de Dios se realiza de los mismos oprimidos. Dios salva al pueblo suscilando a Moisés y haciendo que ćl concientice y movilice al pueblo.

Evidentemente de aqui se desprende una eclesiologia abierta a este clamor, una oración que lo integra solidariamente, unos sacramentos que sean la oración eficaz de la Iglesia que clama por boca de Cristo asumiendo todo el clamor del pueblo por el reino. ${ }^{26}$ en fin una vida religiosa que esté atenta al clamor de los pobres. 27

Podríamos decir, reformulando el viejo axioma teológico lex orandi, lex credendi ${ }^{28}$ (la oración es norma y fuente de la fe), por lex clamandi, lex credendi: sólo una fe que escuche el clamor de los pobres será auténtica. El fides ex auditu (la fe proviene de la escucha) de $\mathrm{Rm} \mathrm{10,17,} \mathrm{se} \mathrm{debe} \mathrm{entender} \mathrm{no} \mathrm{sólo} \mathrm{co-}$ mo escucha de la predicación evangélica, sino lambién como escucha del clamor del pueblo, es decir como auscultación de este signo principal de nuestro tiempo. Sólo bajo estas conclusiones, la Iglesia podrá anunciar la palabra de forma creible.

Interpelación práctica.¿Qué significa esta actilud de escucha del clamor del pueblo? Se trata de eliminar el clamor, liberándolo de las causas de la injusticia, de anular los efectos negativos del pecado en la historia, haciendo presente en la historia la gracia de forma concreta y objetiva. Se trata de hacer que los que lloran, rian del gozo auténtico de la liberación.

Para ello hay que comenzar con hacer una opción preferencial por los pobres en el sentido de Medellin y Puebla (Puebla I134-1165), lo cual es ya una toma de postura profética: en un mundo dividido por la injusticia, se opta por 
los que padecen sus consecuencias dolorosas. Esto, como hemos visto implice una profunda conversión.

Pero ¿cómo concretar esta opción en la práctica, aun supuesta la conversión de mentalidad y de actitudes?. Hay tres respuestas posibles.

La ayıda asistencial. Esta siempre será necesaria y más en momentos de emergencia. Pertenece a la tradición de la iglesia, no se puede descartar, y halla en la madre Teresa de Calcuta su simbolo más concreto hoy. No deja de ser una critica del sistema injusto imperante. Pero esta actitud en la medida que no busca transformar las estructuras y erradicar las causas de la injusticia, resulta insuficiente e incluso ambigüa, pues permite aliviar la mala conciencia de los paises y sectores ricos a través de ayudas benéficas.

La promoción y el desarrollo. Consiste en fomentar el progreso del pueblo a través de técnicas, proyectos sanitarios o agricolas, reformas, etc. Evidentemente es una cooperación más profunda que la anterior: no regala el pescado, sino que enseña a pescar. Sin embargo, no sólo no toca las raices de la injusticia, sino que fácilmente coopera a que los sectores ya ricos todavía se enriquezcan más con el desarrollo y los pobres se mantengan cada vez más pobres. Los planes de la Alianza por el Progreso acaban fracasando. Por necesaria que sea esta actitud, resulta también insuficiente.

La solidaridad con las aspiraciones de liberación del pueblo. El apoyar a las organizaciones y movimientos populares, ${ }^{30}$ la concientización, el trabajo por la participación popular en la sociedad y la Iglesia, de forma que el pueblo sea el protagonista de su propia historia, parece ser lo más sabio que puede hacer la lglesia ante la situación de sufrimiento del pueblo:

Lo más sabio que puede hacer la Iglesia en el mundo de hoy, me parece a mi, es trabajar por la participación popular genuina, tanto en la sociedad civil como en la lglesia. Esla parece ser el único medio a través del cual podemos encontrar algunas soluciones a los problemas que enfrentamos. Por lo menos es una solución que todavía no hemos probado seriamente, y que tiene el sabor de la paradoja presente a lo largo de loda la Biblia: los últimos serán los primeros. ${ }^{31}$

El evangelio no ofrece técnicas ni politicas concretas, pero sí un marco doctrinal, la premisa mayor, que deberá concretarse con la ayuda de las mediaciones humanas en cada caso. El evangelio evita el fatalismo histórico y corrige el riesgo del fanatismo, ayuda a no caer en la mística de la violencia y a desacralizar la revolución, aunque reconoce que en algunos momentos extremos no se puede excluir según la doctrina tradicional de la Iglesia (Populonum Progressio, No. 31). En todo caso, la Iglesia debe, desde el evangelio, acompanar al pueblo en su marcha liberadora y humanizar los procesos revolucionarios, inspirando el amor y no el odio, el perdón y no la venganza, el respeto a la persona y no su instrumentalización, la libertad y no la dictadura, el desprendimiento del poder y no su apego. El evangelio tiene una gran fuerza humanizadora y liberadora integral.

Esta solidaridad con el pueblo debería llegar a tal identificación con el, 
como Crislo, que más que hablar de opción por los pobres, se deberia vivir y sufrir en su propia carne los sufrimientos del pueblo, de modo que el clamor de la Iglesia fuera el clamor del pueblo y el clamor del pueblo resonara en la lglesia como en carne propia.

Oruro, Bolivia 28 enero 1985.

\section{NOTAS}

1. De los teólogos moderino ceiltrocuropeos quizás los más sensibles al tema del clamor sean J. Molımanı y J.B. Heı. Liste ultino lo centra en la experiencia de Auschwitz y se pregunta, con Adorno, si todas ia es posible hacer teologia despues de Auschwitz; cfr. J.B. Metz, Mós alla de la religion hurguesu. Salamanca. 1982. Desde el tercer mundo hay que decir que Auschwit/ continúa hoy...

2. En el Diccionarior det Varicamo // de Miguel Angel Molina Martinez, Madrid: BAC, 1969, no aparcéen clamor, ni lamenın, ırisıeza, opresión, làgrimas, angustias...

3. I Hausherr, "Penthos. I a doctrine de la componction dans l'Orient Chrétien." Roma, 1944; M. L.ot-Borodine. "Le mystere du "don de larmes" dans l'Orient Chrétien," Vie spirituelle, 48 (1936) 65-110.

4. P. Miranda afirma que el hecho de que Dios escuche el clamor del pueblo y se indigne ante la injusticia, no está ligado sólo a las promesas con Israel, sino que ya es anterior a ellas, tal como aparece en Gn 4,10, escrito iniencionalmente como pre-historia del Exodo. P. Miranda, Marx y la Biblia. Salamanca, 1972, I14-116.

5. Basilio , "De la homilia Destruam horrea," en R. Sierra Bravo, Doctrina social y económica de los Padres de la Iglesia. Madrid, 1967, N. 227, p. 173.

6. Basilio, "Homilia contra los ricos," R. Sierra Bravo, p. 187.

7. Basilio, "Homilia sobre el no apego al mundo," R. Sierra Bravo, p. 205.

8. Juan Crisóstomo, "En el Salmo XLXLIII, 3," MG 55,170, Sierra Bravo, p. 399. Cfr también atros textos en páginas 368,372,390,391 de Sierra Bravo.

9. Juan Crisóstomo, "Homilia II," n. 2-4, MG 55,514s, R. Sierra Bravo, p. 406.

10. Juan Crisostomo, "Homilia LXXXVIII," 3, R. Sierra Bravo, p. 447.

II. Juan Crisóstomo, "Homilia XI," 3, MG 69,93. R. Sierra Bravo, p. 532.

12. Bernardo de Claraval, "Tralado sobre las costumbres y oficios de los obispos," R. Sierra Bravo, 1937.

13. Archivo General de Indias, Quilo 76, clr E. Dussel, El Episcopudo lotinoamericano y la liberación de los pobres 1504-1620, México, 1979, p. 103.

14. Juan del Vallc, carla fechada en 1557. Archivo General de Indias, Quito 78, cfr E. Dussel, o.c., p. 70.

15. Archivo General de Indias, Aud. México, 374.

16. E. Dussel, o.c., p. 98-99.

17. E. Dussel, "Historia de la fe cristiana y cambio social," en AA.VV. Fe y cambio social en America latina. Salamanca, 1973, 65-99.

18. Juan Pablo II, "Homilia en la misma celebrada en el aeropuerto de Namao," Edmonton. Canadá, el 17 de septiembre de 1984, sobre Mateo 25, Páginas, 1984, 65-66, 45-47, texto citado p. 46.

19. I. Ellacuria, "El pueblo crucificado. Ensayo de soleriologia histórica," en Cruz y Resurrección. Presencia y anuncio de una iglesia nueva. México, 1978, 49-82.

20. Bartolome de Las Casas, Hisıria de las Indias, Obras escogidas. Madrid, 1958, II. p, 356.

21. Cfr. V. Codina, De la modernidad a la solidaridad. Lima, 1984; el capifulo "Aprender a orar desde los pobres," 22J-223; "Orar al Dios de la vida," Sol Terrae 72 (1984/4) 27/-280.

22. Ernesto Cardenal, "Salmos 13-14," en Salmos. Buenos Aires, 1969.

23. P. Casaldáliga, Experiencia de Dios y pasión por el pueblo. Sanlander, 1983, p. 235.

24. Cir J. Sobrino, "Espiritualidad y teologia," Revista Latinoamericana de Teologia. I (1984/2) 195-223.

25. Sagrada Congregación para la Doctrina de la fe, Instruccion sobre algunos aspectos de la Teologla de la liberacion, $\mathrm{n}$ l. 
26. Crr V. Codina, "Analogia sacramental: de la Eucarisıia a la solidaridad," en De la modernidad a la solidaridad, p. 151-185, especialmenle p. 176, donde se habla de la eficacia sacramental ex opere operantis (vel parientis) hmmanitaris y de la solidaridad con los pobres.

27. Pablo VI, Evangelica resifficalio, No. 17, "EL grito de los pobres es una interpelación para la pobreza religiosa."

28. DS. 246,3792,3828.

29. Cfr S. Rayan, "Algunas perspectivas para la espiritualidad de hoy," en Vida y reflexion. Lima, 1983, 201-248.

30. "Alentar y favorecer todos los esfuerzos del pueblo por crecer y desarrollar sus propias organizaciones de base, por la reivindicación y consolidación de sus derechos y por la búsqueda de una verdadera justicia," Medellin, 2 Paz, 27.

31. Julio Xavier Labayen, obispo de Infanıas, Filipinas, en Vida y reflexión. Lima, 1983, 251272. 